\title{
Gout - Practicable Interdisciplinary Insights for the Clinician on a Surgeon's Perspective
}

\author{
Ingo Schmidt*
}

Medical Centre Wutha-Farnroda (Department of Orthopaedics), Gothaer Str. 67, 99848 Wutha-Farnroda (Germany)

Received: September 18, 2018; Accepted: October 18, 2018; Published: October 30, 2018

*Corresponding author: Ingo Schmidt, Medical Centre Wutha-Farnroda (Department of Orthopaedics), Gothaer Str. 67, 99848 Wutha-Farnroda (Germany), E-mail: schmidtingo62@googlemail.com

\begin{abstract}
Gout is a common systemic metabolic disease caused either by increased uric acid production or by decreased uric acid excretion potentially leading to crystal deposition of monosodium urate in various tissues and resulting in acute gouty attacks mainly initially presenting as mono arthritis of joints. The further course can be accompanied with development of chronic tophaceous gout with or without complications such as skin perforation of tophi accompanied with occurrence of chronic fistula and overlying bacterial infection. When the diagnostic management was early and sufficiently done, it can be successfully treated by specific drugs in most cases, and approximately in up to $5 \%$ of cases only surgical intervention becomes necessary that includes various extremity- and motion-preserving procedures, but in life threatening conditions primary amputation as well. The aim of this article is to present practicable interdisciplinary insights of the disease for clinicians on a view of a surgeon.
\end{abstract}

Key words: Gout; Diagnosis; Clinical presentation; Differential diagnoses; Treatments;

\section{List of Abbreviations}

GA: gouty arthritis

MTPJ: metatarsophalangeal joint

MSU: monosodium urate

HU: hyperuricemia

CTG: chronic tophaceous gout

UA: uric acid

CT: computed tomography

MRI: magnetic resonance imaging

OA: osteoarthritis

RA: rheumatoid arthritis

\section{What is gout?}

Gout is a common systemic metabolic disease affecting up to $2 \%$ of the Western population with an increase of prevalence up to $7 \%$ in patients aged 65 years and older, associated with an overall male-to-female ratio of $3.6: 1$, and the prevalence peaked in men between the ages of 75 and 84 years (7.3\%), while in women its prevalence continued to rise beyond the age of 85 years (being about 2.8\%) [1,2]. This entity was first identified by the ancient Egyptians in 2640 BC, Hippocrates was the first who used the term "podagra" referred to it as "the unwalkable disease" and as an "arthritis of the rich" in the 5th century BC for acute Gouty Arthritis (GA) occurring in the 1st Metatarsophalangeal Joint (MTPJ), 6 centuries later Galen first described the term "tophi" for the crystallized Monosodium Urate (MSU) deposits following longstanding Hyperuricemia (HU), and the alkaloid colchicine, derived from the seeds of the autumn crocus (Colchicum autumnale) (Figure 1), was introduced as a selective and specific treatment for gout by the Byzantine Christian Alexander of Tralles [3].

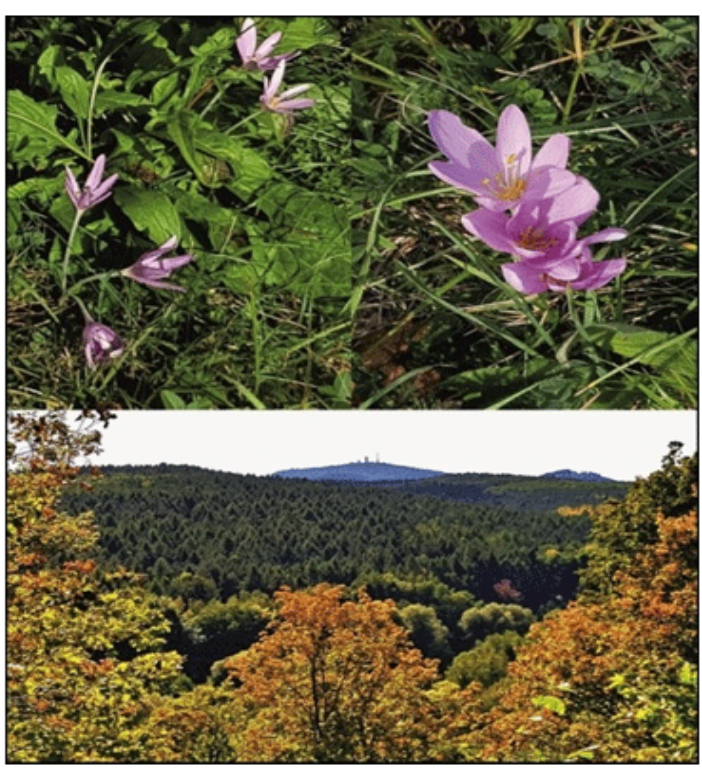

Figure 1: The autumn crocus (Colchicum autumnale), found in the Forest of Thuringia (Germany) near by the "big isle's mountain" on Sept. 16._2018.

Gout is to be classified in 4 four clinical phases: (1) symptomatic or asymptomatic HU, (2) acute GA (initially presented as monoarthritis in up to $90 \%$ of cases, mostly 
podagra), (3) intercritical gout (intervals between acute attacks), and (4) Chronic Tophaceous Gout (CTG) [4,5]. Uric Acid (UA) mainly exists as the urate ion, and as the more acidic un-ionized UA. Humans do not express the enzyme urate oxidase (uricase), because of a mutation during evolution of the uricase gene, which converts urate to the more soluble and easily excreted compound allantoin. Among mammals, only humans and other primate species excrete UA as the end product of purine metabolism [6]. HU may occur either by increased UA production that is found in 5 to $10 \%$ of patients (genetic enzymatic defects or acquired causes such as dietary indiscretions with purine-rich meat and fish, alcohol abuse, obesity, or excessive muscle activities accompanied with an increased purine metabolism) or by decreased UA excretion that is found in 90 to $100 \%$ of patients (genetic causes or acquired various kidney diseases leading to impaired renal function), and approximately $80 \%$ of the gout patients have a positive family history of gout or $\mathrm{HU}[6,7]$. An increased serum UA level may exceed the solubility of the urate and imparts the risk of its crystal deposition as MSU which activates the monocytes producing the NALP3 inflammasome and subsequently leading to the liberation of various inflammatory mediators such as the interleukin 1 in soft tissues surrounding joints at the upper and lower extremity, nerves often firstly presented as peripheral nerve compression syndrome, cartilage, bones, but also in the eye and heart valve, and at the ear from the supersaturated fluids (Figures 2A-2C, 4, 5A-5C, 6A-6D, and 7A-7B) [7-17].

\section{Diagnosis of Gout}

One problem is that a majority of patients with gout present to and are being cared for by nonspecialists, and the management remains suboptimal [18-23]. For diagnosis of gout in routine clinical practice the New York criteria from 1966 are still helpful when 2 of these criteria are present: (1) at least 2 acute attacks of painful joint swelling with complete resolution within 2 weeks if untreated, (2) a clear history of podagra, (3) the presence of a tophus, and (4) a rapid response to colchicine within 48 hours of starting treatment; in comparison to the formerly introduced Rome criteria the response of colchicine was added and the serum UA level ( $>7 \mathrm{mg} / \mathrm{dl}$ in men $/>6 \mathrm{mg} / \mathrm{dl}$ in women) was removed [6]. Under clinical aspects, a tophus is defined as a draining or chalk-like subcutaneous nodule under transparent skin, often with overlying vascularity [24]. Noted that the serum UA level is primarily increased when starting first symptoms of an acute attack, and then, it often early decreases to normal value within approximately 2 to 3 days later, hence, measuring of the serum UA level during the initial attack and at least 2 weeks later is required, and if its level at this time later is not increased (if untreated by drugs) then the diagnosis of gout is unlikely [2527]. However, probably the best investigation for establishing a definite diagnosis of gout is the presence of MSU crystals in aspirated joint fluids or tophus, but joint fluids should ideally be examined within 6 hours after its aspiration to minimize the risk of artefactual results $[6,9,28,29]$. Noted that MSU crystals are not radio opaque and are identified on polarized microscopy as negatively birefringent, and MSU crystals in synovial fluid are observed in more than $95 \%$ of patients with acute GA, but in some asymptomatic patients, MSU crystals are also detected in joints in which there is no inflammation [6,30,31,32]. MSU crystals in soft tissues around joints are well identified by dual energy computed tomography and Computed Tomography (CT) can clearly demonstrate tophi growing into the adjacent bones, ultrasound with Doppler imaging and Magnetic Resonance Imaging (MRI) with contrast showing increased vascularity with inflammation surrounding crystal deposits, and MRI is the only clinical imaging which accurately shows bone marrow edema [7].

\section{Clinical presentation and differential diagnoses of gout}

Typically, the acute attack of GA often begins at night mostly presenting in up to $50 \%$ of cases as monoarthritis of the 1st MTPJ (Figure 2A-C). In decreasing order, other joints can be involved such as ankle and insteps, knees, wrist (Figure 3), fingers, and the olecranon or prepatellar bursae $[33,34,35]$. Symptoms are agonizing pain around the swollen and reddened joint, fatigue, fever, and chills, but noted that GA is often less severe in elderly than in younger patients potentially leading to the misdiagnosis as having a non-specific Osteoarthritis (OA) especially at the finger joints (Heberden OA) [36,37]. The further course can be associated with polyarticular involvement which tends to be less abrupt in onset and less severely painful $[30,38]$. Primary acute polyarticular GA attacks are uncommon, more often observed in elderly patients, and often associated with a positive family history [39]. CTG usually develops 10 or more years after the first gout episode, and tophi may be the initial manifestation of the disease as well $[6,40]$.

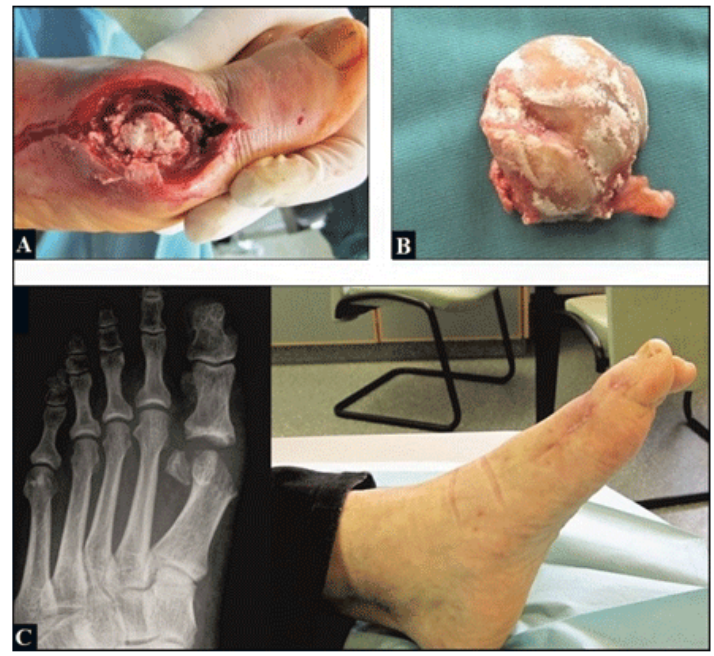

Figure 2: (62-year-old male): (A) Advanced stage of CTG at his left 1st MTPJ (clinical photograph after surgical incision). (B) A resection arthroplasty was performed, note the severe cartilage destruction associated with multiple crystal deposits on the particular surface of the 1st metatarsal head. (C) The postoperative course was uneventful.

Generally, gout must be demarcated from the also crystalinduced arthropathy pseudogout following deposition of calcium pyrophosphate dihydrate, first described as "pseudogout syndrome" by Kohn et al. in 1962 [41], which is probably the 


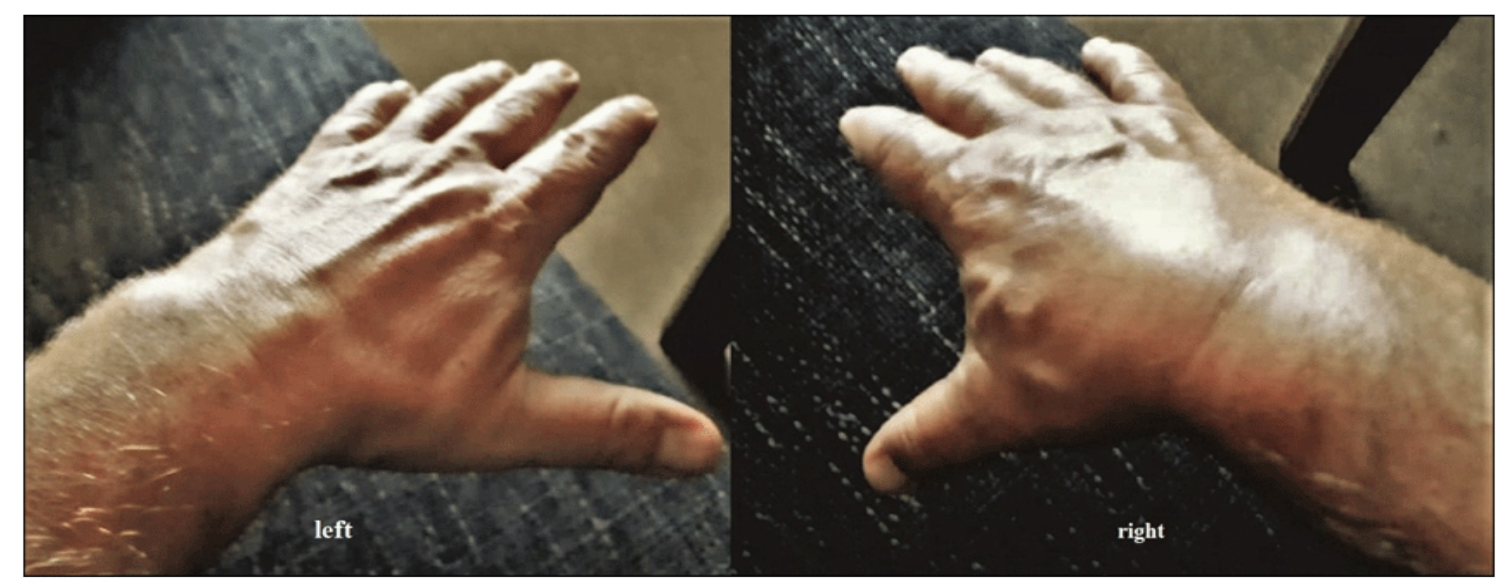

Figure 3: (49-year-old male): Acute GA monoattack at his right wrist with painful swelling

acutest form of arthritis in the elderly, but associated with a relatively rare monoarticular involvement [42-45]. Pseudogout includes at least 6 presentations: (1) acute pseudogout, (2) asymptomatic chondrocalcinosis, (3) pseudo-OA (with or without acute attacks), (4) pseudo-Rheumatoid Arthritis (RA), (5) pseudo-polymyalgia rheumatica, and (6) pseudo-neuropathic arthropathy that can resemble a neuropathic Charcot's joint [46]. The prevalence of pseudogout among younger people is unknown, a major gender pre $\neg$ dominance do not exist, attacks of acute pseudogout appear more commonly in men, and women more fre $\urcorner$ quently exhibiting the pseudo-OA pattern of the disease $[47,48]$. The knee is most commonly involved, followed by the wrist, ankle, elbow, toe, shoulder and hip. Compared with true GA, pseudogout attacks may take longer to reach peak intensity and may persist for up to 3 months despite therapy [49]. Noted that acute pseudogout attacks can be provoked postoperatively by abrupt changes in serum calcium levels such as observed after parathyroidectomy, and after partial thyreoidectomy as well $[42,50]$.

The main differential diagnosis for CTG is Rheumatoid Arthritis (RA). However, GA tends to be less symmetric than typical RA, and the non-chalk-like rheumatoid nodules typically appear polyarticular at the wrist and/or finger joints accompanied with its specific OA-related severe dislocations in volar and ulnar direction (Figure 8A-8C) [6,51]. Other differential diagnoses for CTG are various subcutaneous tumors arising directly from bones, joints or its surrounding tissues (Figures 9A-9H, 10) [52-55]. Chalk-like draining is observed as well from nodules of trichilemmal cysts (Figure 11A-11E), but its appearance at hairless regions such as the fingers is very uncommon, and it was probably first described by Ikegami et al. in 2003 [56-60]. Non-traumatic painful swelling around the wrist and finger joints are also observed by avascular osteonecrosis; furthermore, nontraumatic disruption of the scapholunate ligament can also be initially caused by gout; and moreover, a carpal tunnel syndrome can be the first manifestation of GA as well $[8,11,12,13,14,15,61]$.
Intraosseous appearance of gout presenting as lytic lesions is challenging in diagnostic management [62]. For demarcation of osteomyelitis or intraosseous tumors dual energy computed tomography and/or MRI is the method of choice [7,63,64]. However, histological examination of intraoperatively taken specimens before definite surgical treatment is strictly recommended in order to avoid a failed treatment ( Figure 7A7B) [65].

\section{How is gout treated?}

Treatment of gout is based on 3 main pillars: (1) dietary modification or restriction, (2) medical treatment, and (3) surgical treatment. In 1876, Garrod was among the first to suggest that HU could be controlled by lowering the intake of purine-rich food, and later, Haig confirmed this in a series of clinical experiments he conducted on himself from 1894 to 1897 [3]. In acute GA attack, medical treatment that involves the application of the mitosis inhibitor colchicine which also has an anti-inflammatory effect based on the ability to impair the mobility and activity of neutrophil leucocytes, non-steroidal anti-inflammatory drugs, and maybe also prednisolone should be initiated immediately within 12 to 24 hours that often leads to relief of symptoms within 24 hours [66]. But noted that an overdose of colchicine can be associated with an intoxication presenting as severe nausea, vomiting, and diarrhea; and in single cases with lactic acidosis leading to multiorgan failure with rhabdomyolysis, and death by cardiac arrest [67]. Uricosuric agents, first used at the end of the 19th century, are contraindicated in this phase because its application can provoke further acute attacks $[3,68]$. For the intercritical phase or CTG, the use of the xanthine oxidase inhibitor allopurinol, developed by Rundless et al. in 1963 [69], which acts by inhibiting the synthesis of UA from hypoxanthine and xanthine, is the treatment option of choice. The aim of allopurinol is to decrease the serum UA level below $6,8 \mathrm{mg} / \mathrm{dl}$ in order to avoid deposition of MSU crystals [70,71]. 


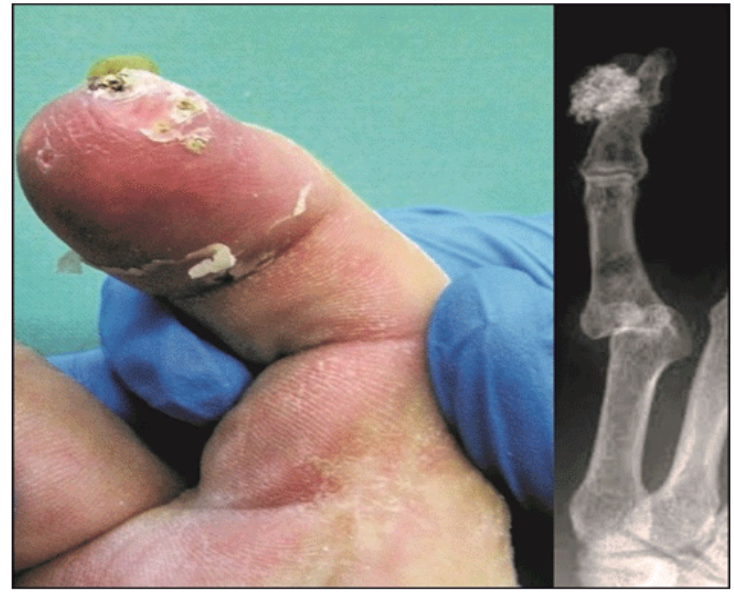

Figure 4: (53-year-old male with a longstanding history of alcohol abuse): Typical chalk-like CTG at the distal interphalangeal joint of his left little finger that led to ulcerations at the fingertip.
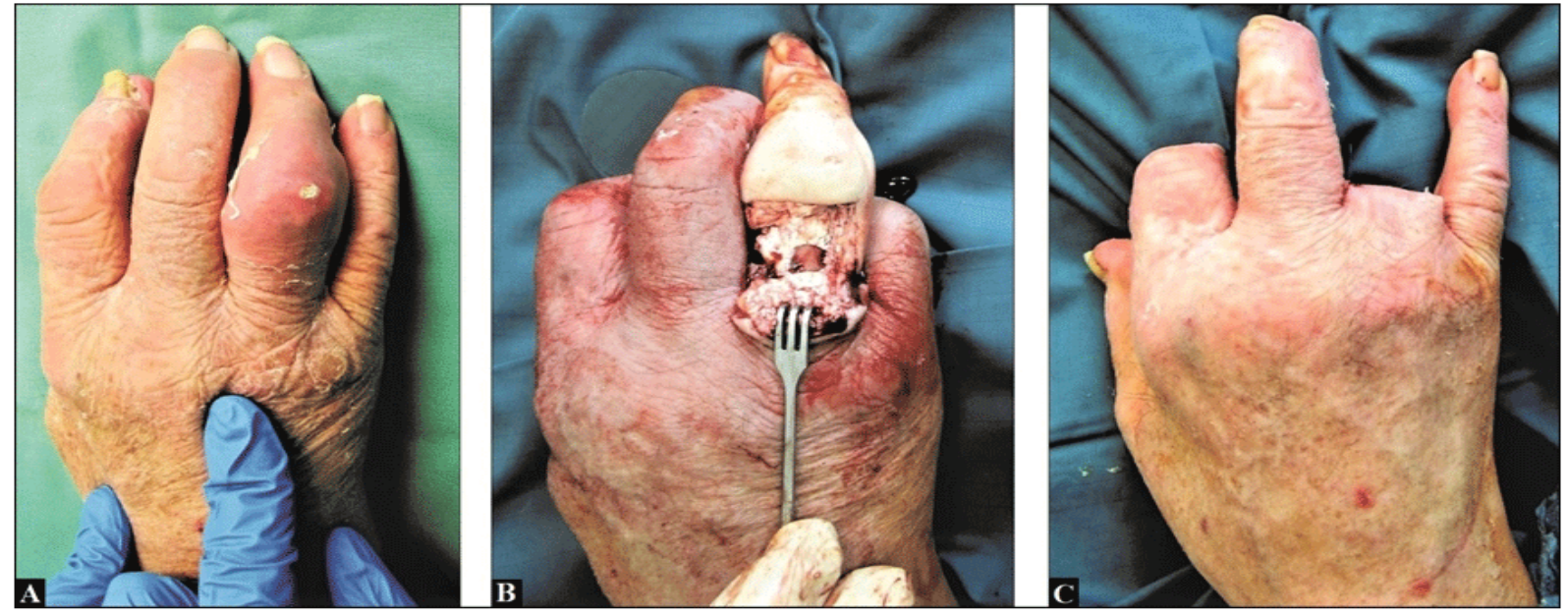

Figure 5: (83-year-old male): (A) Typical CTG with ulcerations and super infection around the proximal interphalangeal joint of the index and distal interphalangeal joint of the little finger at his right hand, noted that there are no joint dislocations. (B) Intraoperative clinical photograph showing the crystal deposits at the index involving the extensor tendon sheath. (C) Primary amputations were done at the metacarpophalangeal joint of the index and proximal interphalangeal joint of the little finger because the patient needed immediately a pacemaker. 

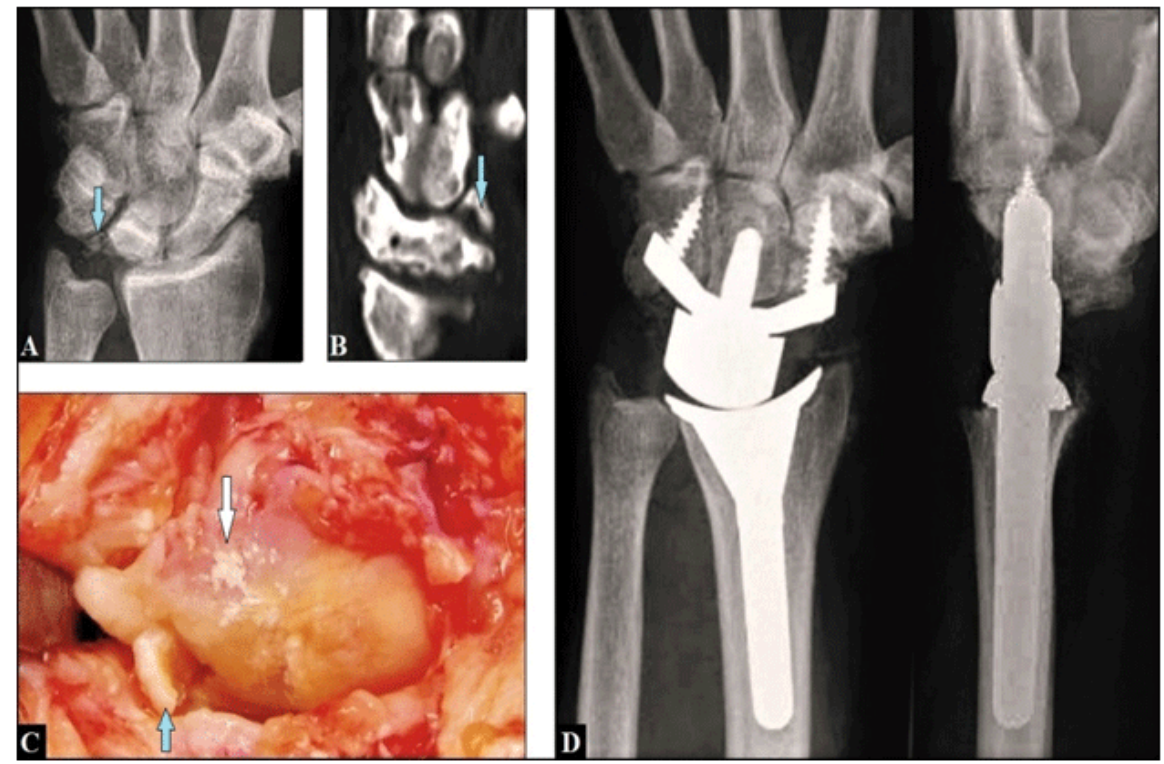

Figure 6: (A 57-year old male presented with a history of drug-resistant arthritis at his left wrist over a period of 2 years [15]): (A) Initial radiograph showing a collapsed and sclerotic lunate bone with surrounding bony fragments (arrow) that suggests Kienböck's disease with its typical stress fractures. (B) Same findings in CT (arrow). (C) Intraoperatively, the severe destructed lunate bone was confirmed (light blue arrow), but there were crystal deposits on the same bone (white arrow), and the diagnosis of gout was confirmed by histological examination. (D) A non-cemented motion-preserving total wrist replacement was performed.

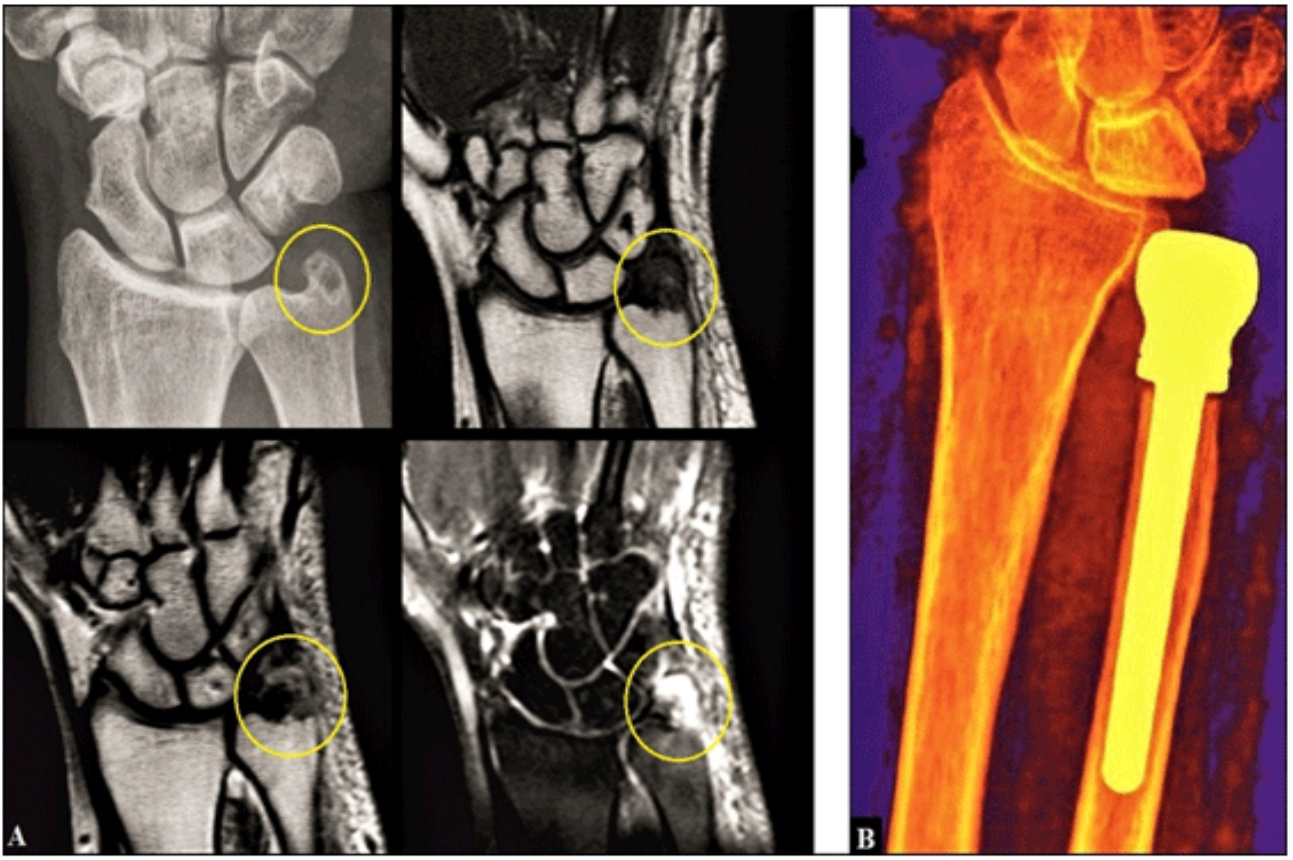

Figure 7: (A 38-year-old male presented with right chronic wrist pain over a period of 2 years): (A) Initial radiograph showing lytic intra osseous lesion at the ulnar styloid (arrow), and MRI showing tumor-like infiltrations of the surrounding soft tissue (arrows) that led to the diagnosis of a possible osteosarcoma with stage T4 by the radiologist, but histological examination of primarily taken specimens revealed gout. (B) A motionpreserving non-cemented ulnar head replacement was performed. 

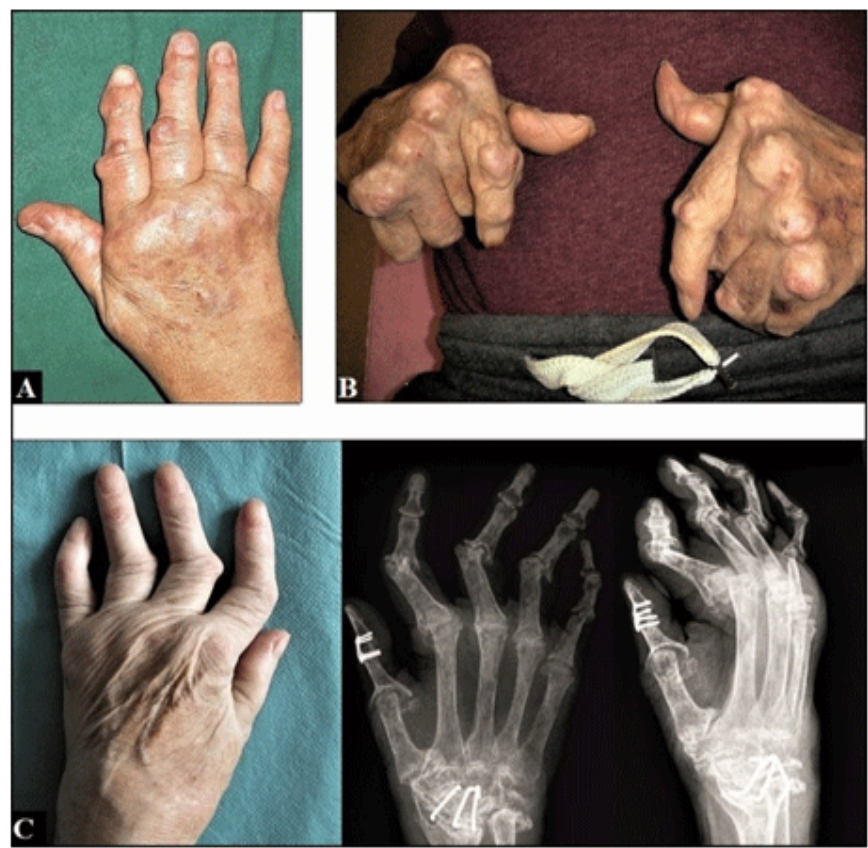

Figure 8: (Typical clinical presentations of RA): (A) Polyarticular non-chalk-like nodules at the finger joints. (B) Typical dislocations at the metacarpophalangeal joints in volar and ulnar direction. (C) Severely arthritic destructions of all joints at the hand with typical dislocations in ulnar direction at the proximal interphalangeal joints II-IV [51].
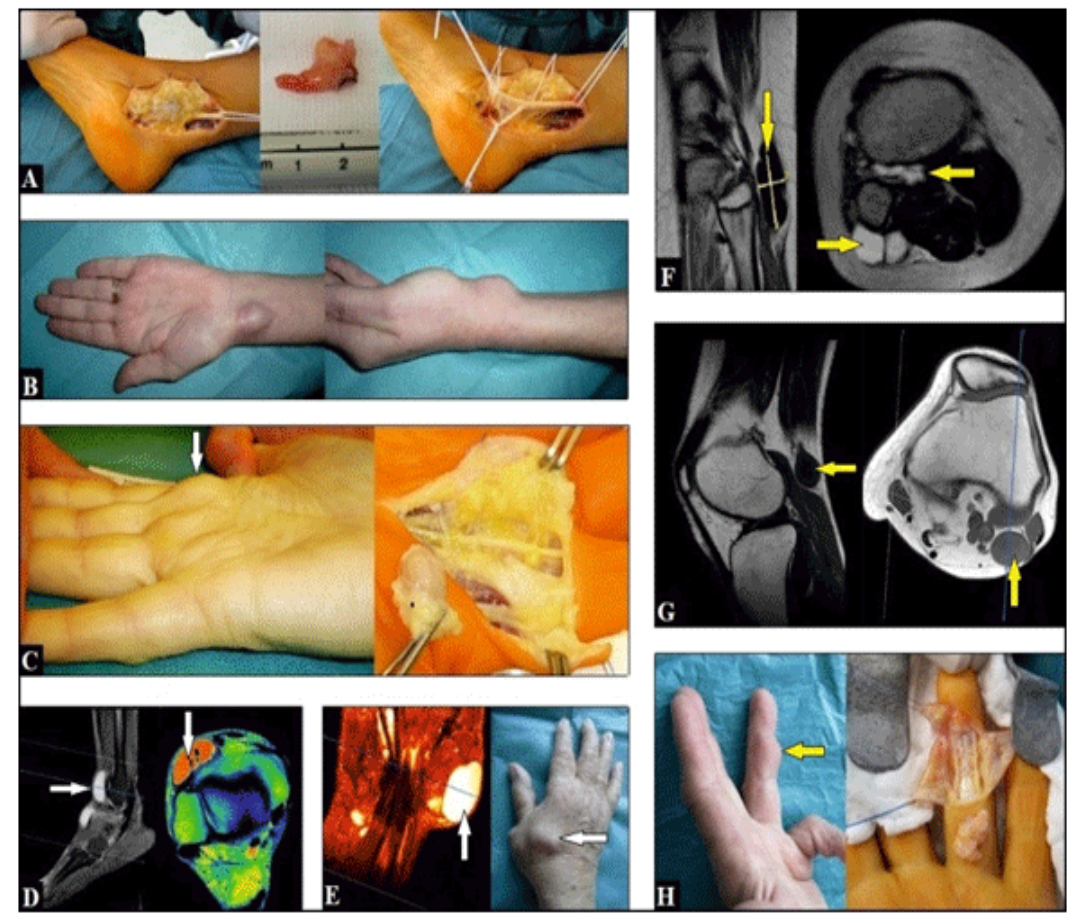

Figure 9: (Painful swellings around joints caused by various tumors): (A) Ganglion cyst of the ankle that led to an entrapment of the posterior tibial nerve (i.e. tarsal tunnel syndrome). (B) Volar wrist ganglion. (C) Giant cell tumor at the volar aspect of the metacarpophalangeal joint (arrow). (D) Ganglion cysts of the tibialis anterior tendon (arrows). (E) Ganglion cyst of the thumb's saddle joint (arrows). (F) Ganglion cyst of the proximal tibiofibular joint (arrows). (G) Schwannoma of the common peroneal nerve (arrows). (H) Chronic granuloma at the volar aspect of the ring finger caused by a previously incorporated foreign body. 


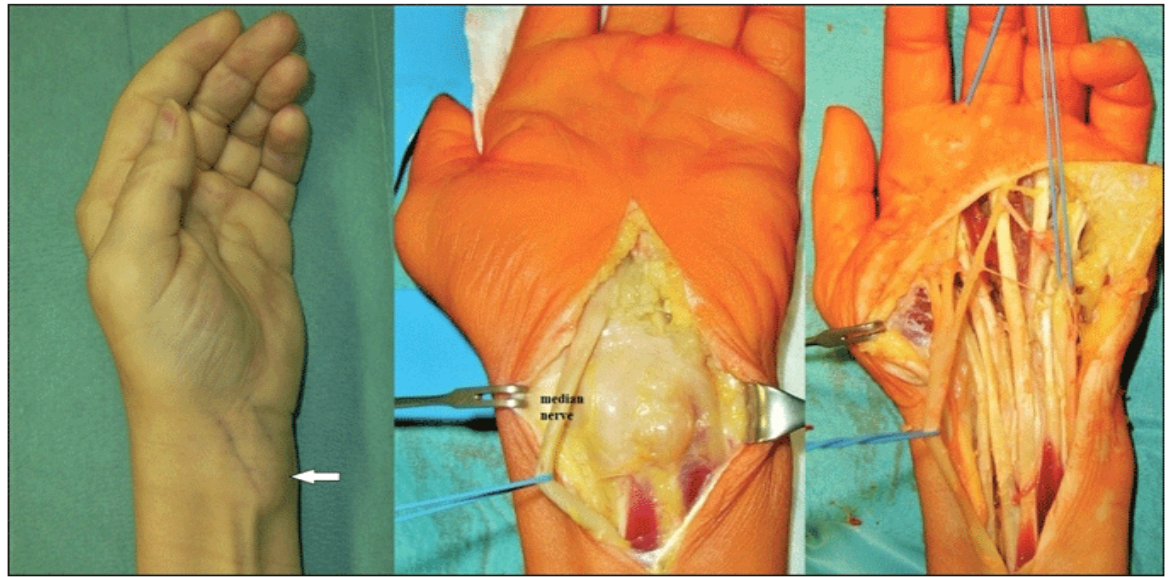

Figure 10: (64-year old female): Monstrous subcutaneous tumor at the volar aspect at her left wrist that led to an entrapment of the median nerve (i.e. carpal tunnel syndrome). A radical debridement of all flexor tendon sheaths was done, and histological examination revealed a giant cell tumor. The postoperative course was uneventful associated with full recovery of neurological deficits.

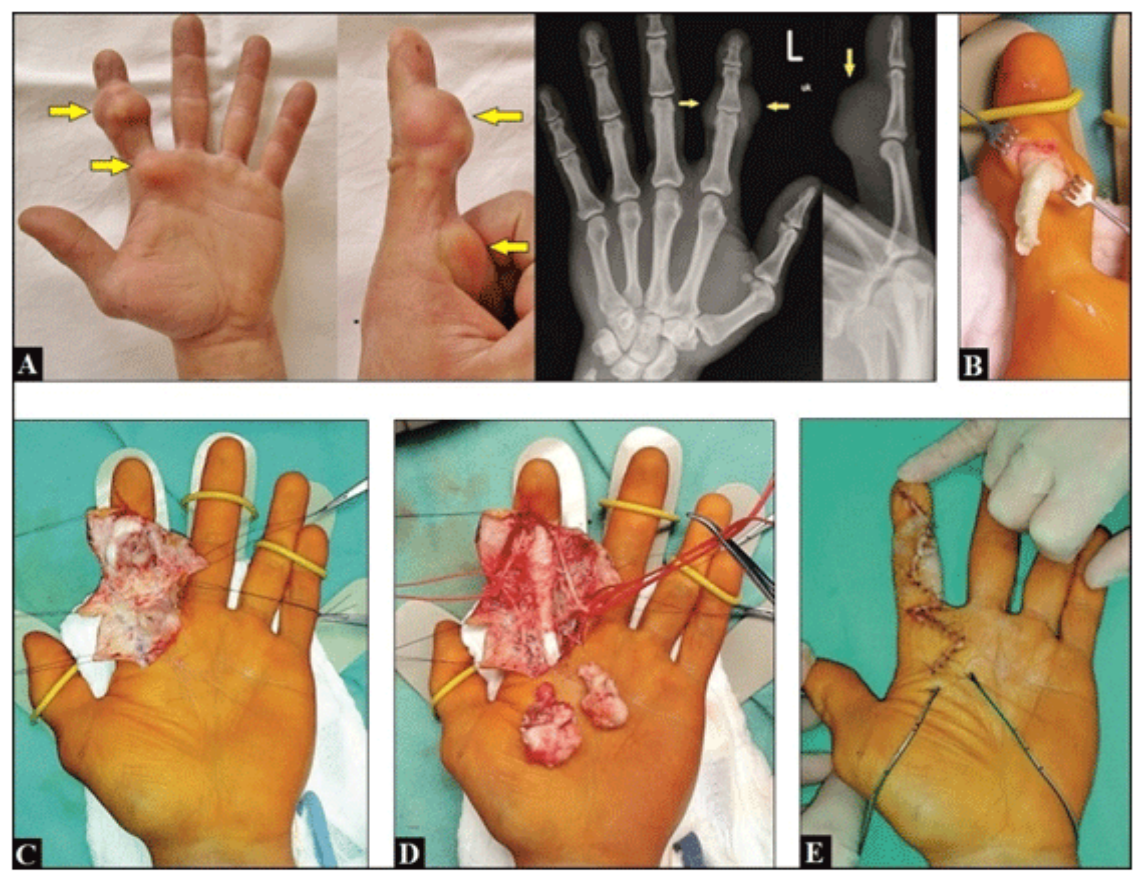

Figure 11: (51-year-old male): (A) Initial findings, the patient reported a history of longstanding progressive growth of subcutaneous tumors at the volar aspects of the metcarpophalangeal and proximal interphalangeal joints of his left index (arrows) over a period of approximately 22 years. (B) Primarily, specimens were taken and there was a white viscous mass resembling chalk-like CTG, but histological examination revealed a trichilemmal cyst. (C) - (E) After correct diagnosis by the pathologist, the 2 trichilemmal cysts were en bloc rejected, and the postoperative course was uneventful. 


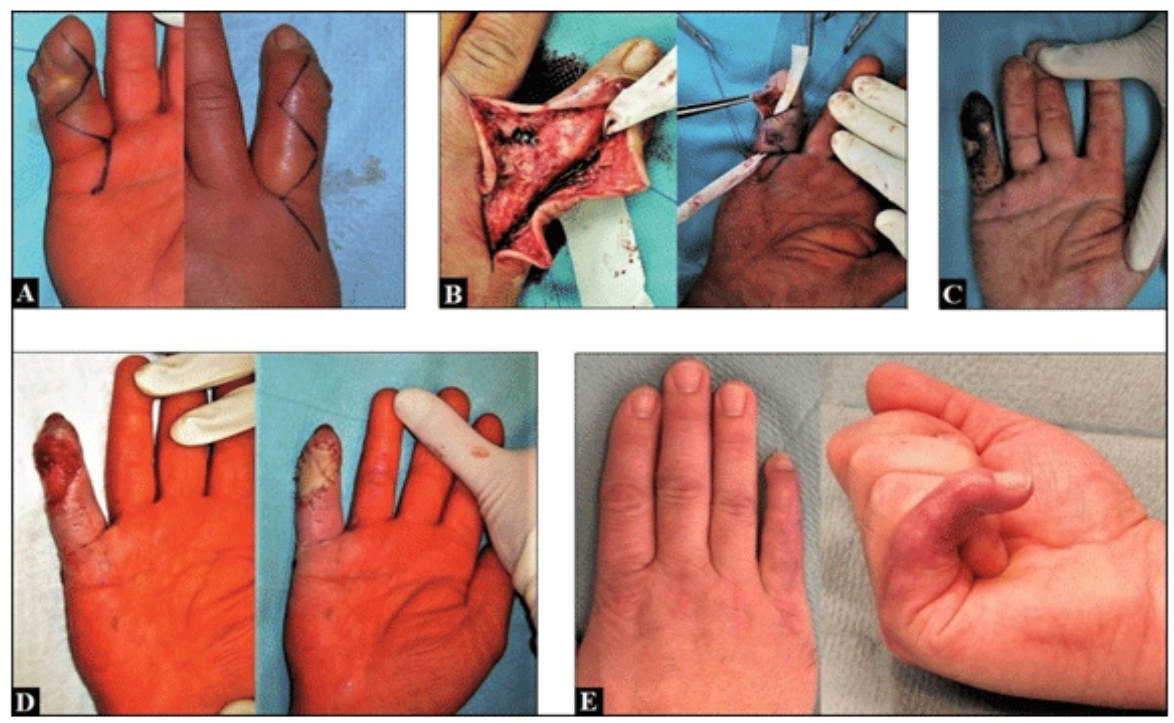

Figure 12: (43-year-old male): (A) Massive phlegmonous bacterial superinfection caused by ulcerating CTG of the overall right little finger. (B) The extremity-preserving radical surgical debridement of all tophi involving all flexor and extensor tendon sheaths was performed. (C) The further course was complicated by development of soft tissue necrosis at the distal phalanx. (D) After removal of the necrosis and wound conditioning the resulting defect could be covered by a skin graft. (E) At the 6-months follow-up there was marked functional loss with an incomplete fist conclusion due to adhesions of the tendons with overlying skin.

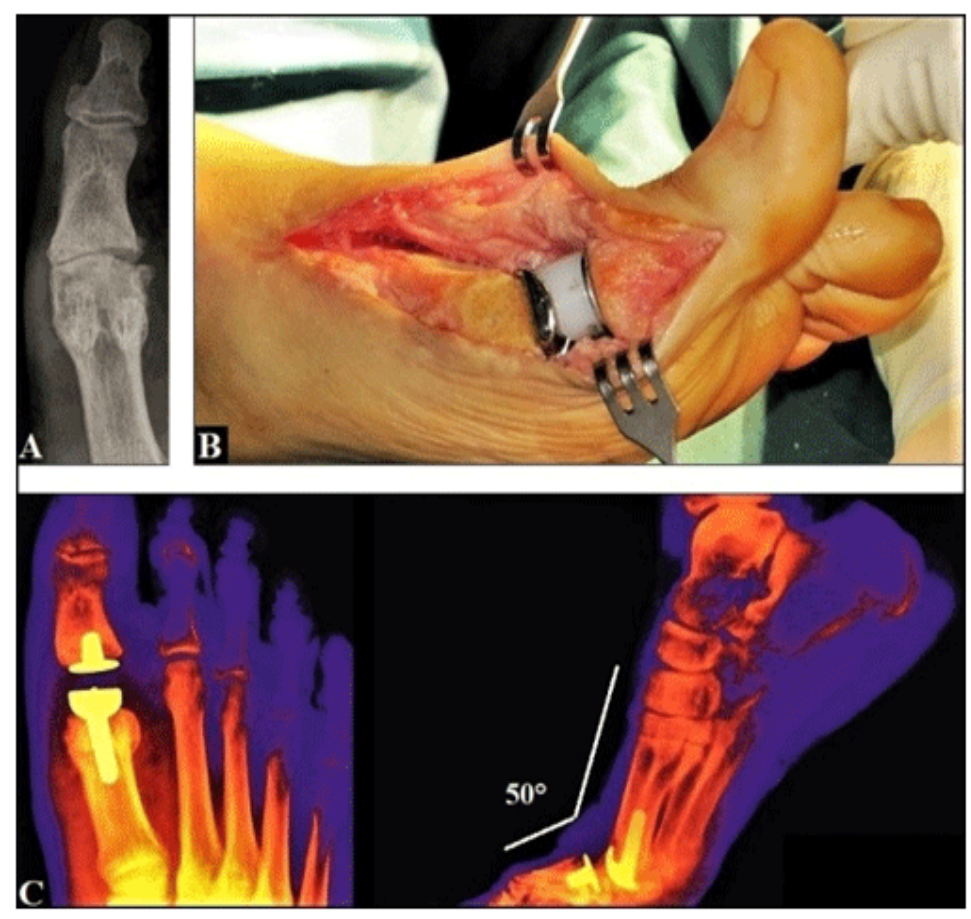

Figure 13: (58-year-old male): (A) Painful advanced stage of OA at his right 1st MTPJ (i.e. hallux rigidus), there was a longstanding history of multiple acute gout attacks (i.e. podagra). (B) A motion-preserving non-cemented total joint replacement was performed. (C) Dynamic radiographs demonstrating the well gait 


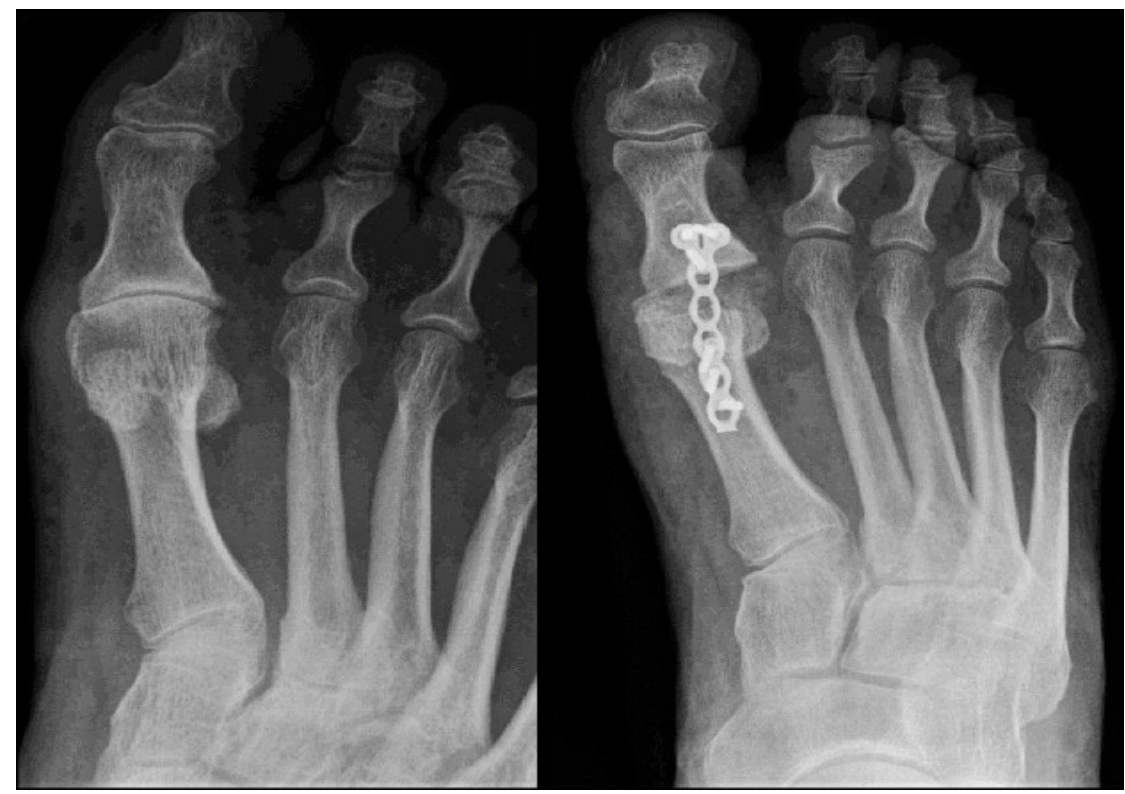

Figure 14: (57-year-old female): Painful advanced stage of OA at her right 1st MTPJ (i.e. hallux rigidus), there was a longstanding history of multiple acute gout attacks (i.e. podagra). Primarily, a motion-preserving total joint replacement was performed, but it has been failed 2 years postoperatively. Therefore, the motion-restricting arthrodesis utilizing a non-vascularized corticocancellous iliac crest bone graft and a titanium plate had to be performed.

When GA is primarily diagnosed, only $5 \%$ of patients may not respond to medical treatment and surgical treatment at the wrist and hand becomes necessary [23]. The most important indications for surgery are longstanding drug-resistant painful joint $\mathrm{OA}$ and pronounced tophi with or without its ulceration potentially leading to chronic fistula and bacterial super infection. Extremity-preserving surgery, that includes radical debridement of tophi with or without coverage of resulting soft tissue defects, should generally be sought, but noted that complete functional recovery often cannot be achieved especially when the tendon sheaths are affected by the gouty inflammation (Figure 12A-12E). Motion-preserving joint surgery can be achieved utilizing partial or total joint replacements (Figures 6A-6D, 7A-7B, and 13A-13C) or resection arthroplasty (Figure 2A-2C), and another option is the motion-restricting joint arthrodesis (Figure 14). Which of these procedures had to be done depends on the patient's claim in activities of daily living. Primary amputation becomes necessary in patients with life-threatening conditions (Figure 5A-5C).

\section{Acknowledgements}

None

\section{Declarations}

The author declares that he has none conflict of interests concerning this article content.

\section{Notification}

The author of this article content is "Winner of the World Academic Championship-2018 in Rheumatology (metacarpophalangeal joints) and Fellow" among 5657 nominations from 53 countries based on the subject "A 10-Year Follow-Up of Uncemented Constrained Metacarpophalangeal Joint Arthroplasties Using the RM Prosthesis in a Patient with Rheumatoid Arthritis" (published in: J Rheumatol Arthritic Dis. 2017;2(1):1-5. [51]), awarded by the Directorate of the International Agency of Standards and Ratings (IASR), and the IASR recognized him among "World's 500 Most Influential Experts in Rheumatology for the year 2018 on earth" [72-75].

\section{References}

1. Annemans L, Spaepen E, Gaskin M, Bonnemaire M, Malier V, Gilbert $\mathrm{T}$, et al. Gout in the UK and Germany: prevalence, comorbidities and management in general practice 2000-2005. Ann Rheum Dis. 2007;67(7):960-966.

2. Mikuls TR, Farrar JT, Bilker WB, Fernandes S, Schumacher HR Jr, Saag KG. Gout epidemiology: Results from the UK general practice research database, 1990-1999. Ann Rheum Dis. 2005;64(2):267-272. doi: 10.1136/ard.2004.024091

3. Nuki G, Simkin PA. A concise history of gout and hyperuricemia and their treatment. Arthritis Res Ther. 2006;8 Suppl 1:S1.

4. Schlesinger N. Management of acute and chronic gouty arthritis: present state-of-the-art. Drugs. 2004;64(21):2399-2416.

5. Taylor WJ, Fransen J, Jansen TL, Dalbeth N, Schumacher HR, Brown M, et al. Study for Updated Gout Classification Criteria (SUGAR): Identification of Features to Classify Gout. Arthritis Care Res (Hoboken). 2015;67(9):1304-1315. doi: 10.1002/acr.22585 
6. Schlesinger N. Diagnosis of gout: clinical, laboratory, and radiologic findings. Am J Manag Care. 2005;11(15 Suppl):S443-S450; quiz S465-S468.

7. Girish G, Melville DM, Kaeley GS, Brandon CJ, Goyal JR, Jacobson JA et al. Imaging appearances in gout. Arthritis. 2013;2013:673401. doi: $10.1155 / 2013 / 673401$

8. Helfgott SM, Skoff H. Scapholunate dissociation associated with crystal induced synovitis. J Rheumatol. 1992;19(3):485-487.

9. Engel B, Just J, Bleckwenn M, Weckbecker K. Treatment Options for Gout. Dtsch Arztebl Int. 2017;114(13):215-222.

10. Martinez-Cordero E, Barriera-Mercado E, Katona G. Eye tophi deposition in gout. J Rheumatol. 1986;13(2):471-473.

11. Champion D. Gouty tenosynovitis and the carpal tunnel syndrome. Med J Aust. 1969;1(20):1030-1032.

12. Ohishi T, Koide Y, Takahashi M, Miyata R, Kushida K. Scapholunate dissociation caused by gouty arthritis of the wrist. Case report. Scand J Plast Reconstr Surg Hand Surg. 2000;34(2):189-191.

13. Lee YH, Tan HW, Lee HC. Wrist gouty arthritis presenting as scaphoid erosions with scapholunate ligament disruption. Singapore Med J. 2008;49(8):e202-e204.

14. Rich JT, Bush DC, Lincoski CJ, Harrington TM. Carpal tunnel syndrome due to tophaceous gout. Orthopedics. 2004;27(8):862-863.

15. Schmidt I. Kienböck's disease mimicking gouty monoarthritis of the wrist. Int J Case Rep Images. 2017;8(6):423-426.

16. Scalapino JN, Edwards WD, Steckelberg JM, Wooton RS, Callahan JA, Ginsberg WW. Mitral stenosis associated with valvular tophi. Mayo Clin Proc. 1984;59(7):509-512.

17. Rott KT, Agudelo CA. Gout. JAMA. 2003;289(21):2857-2860.

18. Keith MP, Gilliland WR. Updates in the management of gout. Am J Med. 2007;120(3):221-224.

19. Mikuls TR, Farrar JT, Bilker WB, Fernandes S, Saag KG. Suboptimal physician adherence to quality indicators for the management of gout and asymptomatic hyperuricaemia: results from the UK General Practice Research Database (GPRD). Rheumatology (Oxford). 2005;44(8):1038-1042. doi: 10.1093/rheumatology/keh679

20. Singh JA, Hodges JS, Toscano JP, Asch SM. Quality of care for gout in the US needs improvement. Arthritis Rheum. 2007;57(5):822-829.

21. Wolfe F, Cathey MA. The misdiagnosis of gout and hyperuricemia. J Rheumatol. 1991;18(8):1232-1234.

22. Chui CH, Lee JY. Diagnostic dilemmas in unusual presentations of gout. Aust Fam Physician. 2007;36(11):931-934

23. Tang CY, Fung B. The last defence? Surgical aspects of gouty arthritis of hand and wrist. Hong Kong Med J. 2011;17(6):480-486.

24. Neogi T, Jansen TL, Dalbeth N, Fransen J, Schumacher HR, Berendsen D, et al. 2015 Gout classification criteria: an American College of Rheumatology/European League Against Rheumatism collaborative initiative. Ann Rheum Dis. 2015;74(10):1789-1798. doi: 10.1136/ annrheumdis-2015-208237

25. Urano W, Yamanaka H, Tsutani H, Nakajima H, Matsuda Y, Taniguchi A, et al. The inflammatory process in the mechanism of decreased serum uric acid concentrations during acute gouty arthritis. J Rheumatol. 2002;29(9):1950-1953.

26. Shoji A, Yamanaka H, Kamatani N. A retrospective study of the relationship between serum urate level and recurrent attacks of gouty arthritis: evidence for reduction of recurrent gouty arthritis with antihyperuricemic therapy. Arthritis Rheum. 2004;51(3):321-325. doi: 10.1002/art.20405

27. Rigby AS, Wood PH. Serum uric acid levels and gout: what does this herald for the population? Clin Exp Rheumatol. 1994;12(4):395-400.

28. McCarty DJ, Hollander JL. Identification of urate crystals in gouty synovial fluid. Ann Intern Med. 1961;54:452-460.

29. Wallace SL, Robinson H, Masi AT, Decker JL, McCarty DJ, Yü TF. Preliminary criteria for the classification of the acute arthritis of primary gout. Arthritis Rheum. 1977;20(3):895-900.

30. Lawry GV 2nd, Fan PT, Bluestone R. Polyarticular versus monoarticular gout: a prospective, comparative analysis of clinical features. Medicine (Baltimore). 1988;67(5):335-342.

31. Weinberger A, Schumacher HR, Agudelo CA. Urate crystals in asymptomatic metatarsophalangeal joints. Ann Intern Med. 1979;91(1):56-57.

32. Bomalaski JS, Lluberas G, Schumacher HR Jr. Monosodium urate crystals in the knee joints of patients with asymptomatic nontophaceous gout. Arthritis Rheum. 1986;29(12):1480-1484.

33. Grahame R, Scott JT. Clinical survey of 354 patients with gout. Ann Rheum Dis. 1970;29(5):461-468.

34. Jelley MJ, Wortmann R. Practical steps in the diagnosis and management of gout. BioDrugs. 2000;14(2):99-107.

35. Harris MD, Siegel LB, Alloway JA. Gout and hyperuricemia. Am Fam Physician. 1999;59(4):925-934.

36. Campbell SM. Gout: how presentation, diagnosis and treatment differ in the elderly. Geriatrics. 1988;43(11):71-77.

37. Lally EV, Zimmerman B, Ho G Jr, KaplanSR. Uratemediated inflammation in nodal arthritis: clinical and roentgenographic correlations. Arthritis Rheum. 1989;32(1):86-90.

38. Raddatz DA, Mahowald ML, Bilka PJ. Acute polyarticular gout. Ann Rheum Dis. 1983;42(2):117-122.

39. Dore RK. The gout diagnosis. Cleve Clin J Med. 2008;75 Suppl 5:S17-S21.

40. Wernick R, Winkler C, Campbell S. Tophi as the initial manifestation of gout. Report of six cases and review of the literature. Arch Intern Med. 1992;152(4):873-876.

41. Kohn NN, Hughes RE, McCarty DJ Jr, Faires JS. The significance of 
calcium phosphate crystals in the synovial fluid of arthritic patients: the „pseudogout syndrome“. II. Identification of crystals. Ann Intern Med. 1962;56:738-745.

42. Kocyigit F, Kuyucu E, Kocyigit A. Monoarticular hip involvement in pseudogout. Case Rep Rheumatol. 2015;2015:302389. doi: $10.1155 / 2015 / 302389$

43. Dala-Ali BM, Welck M, Lloyd MA, Atkinson HD. Pseudogout Associated Hip Pain in a Patient with HIV Infection. Case Rep Med. 2010;2010:842814. doi: 10.1155/2010/842814

44. Mukhopadhyay S, Guha A, Perera A. Monoarticular pseudogout of the hip presenting as septic arthritis: a case report. Acta Orthop Traumatol Turc. 2011;45(3):200-202.

45. Hamilton LC, Biant LC, Temple LN, Field RE. Isolated pseudogout diagnosed on hip arthroscopy. J Bone Joint Surg Br. 2009;91(4):533535. doi: 10.1302/0301-620X.91B4.21707

46. Macmullan P, McCarthy G. Treatment and management of pseudogout: insights for the clinician. Ther Adv Musculoskelet Dis. 2012;4(2):121131. doi: $10.1177 / 1759720 X 11432559$

47.0'Duffy JD. Clinical studies of acute pseudogout attacks: comments on prevalence, predispositions, and treatment. Arthritis Rheum. 1976;19(Suppl 3):349-352.

48. Rosenthal A, Ryan, LM, McCarty DJ. Calcium pyrophosphate deposition disease, pseudogout, and articular chondrocalcinosis. In: Koopman WJ and Moreland LW (eds), Arthritis and Allied Conditions. 2005, 15th ed. Philadelphia: Lippincott Wiliams \& Wilkins, p. 273.

49. Masuda I, Ishikawa K. Clinical features of pseudogout attack. A survey of 50 cases. Clin Orthop Relat Res. 1988:173-181.

50. Bilezikian JP, Connor TB, Aptekar R, Freijanes J, Aurbach GD, Pachas WN, et al. Pseudogout after parathyroidectomy. Lancet. 1973;301(7801):445-446.

51.Schmidt I. A 10-Year Follow-Up of Uncemented Constrained Metacarpophalangeal Joint Arthroplasties Using the RM Prosthesis in a Patient with Rheumatoid Arthritis. J Rheumatol Arthritic Dis. 2017;2(1):1-5.

52. Schmidt I. Posttraumatic ulnar carpal translocation type I accompanied with disruption of the lunotriquetral ligament caused by a severe radiocarpal fracture-dislocation injury type II accompanied with complete luxation of the distal radioulnar joint. What are the salvage options with ist special features in indication when patients develop posttraumatic painful wrist joint osteoarthritis. Trauma Emerg Care. 2017;2(4):1-5. doi: 10.15761/TEC.1000138

53. Schmidt I. Entrapment of the Common Peroneal Nerve due to Multiple Hereditary Exostoses with Synostosis of the Proximal Tibiofibular Joint. J Musculoskelet Disord Treat. 2017;3(2):1-3.

54. Schmidt I. Giant Lipoma of the Thenar leading to Entrapment of All Peripheral Long Finger Branches of the Median Nerve: Case Report.
JSM Clin Case Rep. 2017;5(1):1125.

55.Schmidt I. Common peroneal nerve palsy caused by an initially misdiagnosed extraneural and intraneural benign ganglion cyst of the peroneal nerve in a 11-year-old child: A rare but severe condition. Int J Case Rep Images. 2017;8(9):623-626.

56. Ikegami T, Kameyama M, Orikasa H, Yamazaki K. Trichilemmal cyst in the pulp of the index finger: a case report. Hand Surg. 2003;8(2):253255.

57. Choi CM, Cho HR, Lew BL, Sim WY. A Case of Trichilemmal Cyst oft he Finger. Korean J Dermatol. 2009;47(8):945-947.

58. El Hassani Y, Beaulieu JY, Tschanz E, Marcheix PS. Proliferating trichilemmal tumor of the pulp of a finger: case report and review of the literature. Chir Main. 2013;32(2):117-119. doi: 10.1016/j.main.2013.02.002

59. Melikoglu C, Eren F, Keklik B, Aslan C, Sutcu M, Zeynep Tarini E. Trichilemmal cyst of the third fingertip: a case report. Hand Surg. 2014;19(1):131-133. doi: 10.1142/S0218810414720113

60. Kwon KE, Kim SJ, Kim JH, Jung YY, Park NH, Park JY, et al. Imaging sonographic findings of in a case of proliferating trichilemmal tumor of a finger: A case report. J Clin Ultrasound. 2018;46(3):215-217. doi: $10.1002 /$ jcu.22500

61.Schmidt I. The idiopathic avascular osteonecrosis of the third metacarpal head (M. Mauclaire/Dieterich's disease). Int J Case Rep Images. 2017;8(2):92-95.

62. Schuind FA, Van Geertruyden J, Stallenberg B, Remmelink M, Pasteels JL. A rare manifestation of gout at the wrist--a case report. Acta Orthop Scand. 2002;73(5):594-596. doi: 10.1080/000164702321022910

63. Tehranzadeh J, Ashikyan 0, Dascalos J, Dennehey C. MRI of large intraosseous lesions in patients with inflammatory arthritis. AJR Am J Roentgenol. 2004;183(5):1453-1463. doi: 10.2214/ajr.183.5.1831453

64. An JW, Troster SM. Lytic Bone Lesions: Osteomyelitis or Intraosseous Gout. J Rheumatol. 2017;44(9):1410-1411. doi: 10.3899/ jrheum. 170125

65. Schmidt I. An Unusual and Complicated Course of a Giant Cell Tumor of the Capitate Bone. Case Rep Orthop. 2016;2016:3705808. doi: 10.1155/2016/3705808

66. van Durme CM, Wechalekar MD, Buchbinder R, Schlesinger N, van der Heijde D, Landewé RB. Non-steroidal anti-inflammatory drugs for acute gout. Cochrane Database Syst Rev. 2014;16(9):CD010120. doi: 10.1002/14651858.CD010120.pub2

67. Erden A, Karagoz H, Gümüscü HH, Karahan S, Basak M, Aykas F, et al. Colchicine intoxication: a report of two suicide cases. Ther Clin Risk Manag. 2013;9:505-509. doi: 10.2147/TCRM.S54558

68. Khanna D, Khanna PP, Fitzgerald JD, Singh MK, Bae S, Neogi T, et al. 2012 American College of Rheumatology guidelines for management of gout. Part 2: therapy and antiinflammatory prophylaxis of acute 
gouty arthritis. Arthritis Care Res (Hoboken). 2012;64(10):1447-1461. doi: 10.1002/acr.21773

69. Rundles RW, Wyngaarden JB, Hitchings GH, Elion GB, Silberman HR: Effects of a xanthine oxidase inhibitor on thiopurine metabolism, hyperuricaemia and gout. Trans Assoc Am Physicians. 1963;76:126140.

70.Zhang W, Doherty M, Bardin T, Pascual E, Barskova V, Conaghan $\mathrm{P}$, et al. EULAR evidence based recommendations for gout. Part II: Management. Report of a task force of the EULAR Standing Committee for International Clinical Studies Including Therapeutics (ESCISIT). Ann Rheum Dis. 2006;65(10):1312-1324. doi: 10.1136/ ard.2006.055269
71. Khanna D, Fitzgerald JD, Khanna PP, Bae S, Singh MK, Neogi T, et al. 2012 American College of Rheumatology guidelines for management of gout. Part 1: Systematic nonpharmacologic and pharmacologic therapeutic approaches to hyperuricemia. Arthritis Care Res (Hoboken). 2012;64(10):1431-1446. doi: 10.1002/acr.21772

72.https://sites.google.com/site/internationalindexing/home/worldacademic-championship/world-academic-championship-2018-inrheumatology-metacarpophalangeal-joints-press-release

73. https://sites.google.com/site/usanewscorp/home/dr-ingo-schmidtfrom-germany-wins-world-academic-championship-2018-inrheumatology-metacarpophalangeal-joints

74.https://symbiosisonlinepublishing.com/rheumatology-arthriticdiseases

75.https://www.springermedizin.de/personalia/15611706 